\title{
A EDUCAÇ̃̃O EM GÊNERO E DIVERSIDADE SEXUAL NA PROMOÇ̃̃O DA IGUALDADE DE GÊNERO: A CONQUISTA DA CIDADANIA NEGRA
}

\author{
EDUCATION IN GENDER AND SEXUAL DIVERSITY TO PROMOTE GENDER EQUALLTYY: THE CONQUEST OF \\ BLACK CITIZENSHIP
}

\section{RESUMO}

A criação de legislações e jurisprudências destinadas à proteção das relações de gênero e diversidade sexual tiveram um avanço nas últimas décadas. Todavia, apesar do assunto despertar alguns debates, ainda se percebe um desconhecimento mais profundo sobre a temática, bem como da importância de se discuti-la na seara educacional, uma vez que esse também é um espaço de reconhecimento/respeito às diferenças, construção de identidades e, principalmente, fruição da cidadania. Sendo assim, a justificativa social de uma pesquisa sobre o assunto está relacionada a trazer a visibilidade sobre o tema, bem com abordar a Educação em Gênero e Diversidade Sexual na promoção da igualdade de gênero, em especial à população negra. Para tanto, utilizou-se de pesquisa exploratória e bibliográfica, calcada na legislação e a doutrina pátria e internacional, bem como sites oficiais e não oficiais.

Palavras-chave: Educação em Gênero e Diversidade Sexual. Cidadania. Igualdade de Gênero. População negra.

\section{ABSTRACT}

The creation of legislation and jurisprudence for the protection of gender and sexual diversity relations has made progress in recent decades. However, despite the subject of some debates, there is still a deeper lack of knowledge about the theme, as well as the importance of discussing it in the educational field, since it is also a space of recognition/respect for differences, construction of identities and, above all, preparation for citizenship. Therefore, the social justification of a research on the subject is related to bringing the visibility on the subject, as well as to approach Education in Gender and Sexual Diversity in the promotion of gender equality, especially to the black population. For this, we used exploratory and bibliographic research, based on legislation and the doctrine of the mother country and international, as well as official and unofficial sites.

Keywords: Education in Gender and Sexual Diversity. Citizenship. Gender equality. Black population.

Antônio Rodrigues Neto

Mestre em Direitos Humanos (PPG-DH/UFMS) E-mail: antonio.neeeto@gmail.com

Isabelle Dias Carneiro Santos

Professora na Faculdade de Direito da Universidade Federal do Mato Grosso do Sul (FADIR/ UFMS). Pós-doutoranda em Direito Público pela Universidad de Santiago de Compostela. E-mail: professoraisabellesantos@gmail.com 


\section{Notas introdutórias}

Quando a temática de gênero é abordada, em geral, o imaginário popular faz alusão a uma visão binária de gênero, pela qual as idealizações de masculino e feminino são determinadas desde a descoberta do sexo biológico da criança e irão, inevitavelmente, corresponder ao padrão de homem e mulher culturalmente imposto. Contudo, o gênero vai além dessa concepção, englobando outras formas de expressão e, ainda, existindo paralelamente a outros elementos, tais como orientação sexual ${ }^{1}$, raça, classe econômica, nacionalidade, etc.

Ao tratar do assunto gênero, portanto, é preciso compreender que se trata de uma construção social e que cada indivíduo poderá manifestá-lo à sua maneira, pois é nisso que se fundamenta a sua própria identidade, seja ela dissidente do padrão hétero e cisnormativo ou não. $\mathrm{O}$ gênero, em razão da estrutura social, define as oportunidades/dificuldades e a visibilidade que o indivíduo alcançará em sociedade, dinâmica na qual se inserem as lutas e os direitos das e para as mulheres: sejam elas cis ou trans.

Apesar de a questão de gênero e diversidade sexual ser amplamente exposta na mídia, os debates que desperta são rasos e acabam por criar equívocos que levam à misoginia, homofobia, transfobia, sexismo e crescimento de ações machistas e intolerantes da sociedade, razão pela qual se torna de suma importância discutir o tema na seara acadêmica, seja no que tange à pesquisa cientifica, seja no campo da educação básica, com fins de promoção da igualdade de gênero.

Se a questão feminina vem sendo estudada há algumas décadas, no que tange aos grupos $\mathrm{LGBTI}^{2}$, por outro lado, o assunto é mais recente e, quando envolve os aspectos étnico-racial e econômico, percebe-se um rol ainda menor de pesquisas que se debruçam sobre o tema envolvendo a problemática de gênero e diversidade sexual da população negra no país.

Dessa forma, o objetivo principal desse trabalho consiste em compreender de que forma a Educação em Gênero e Diversidade Sexual, enquanto educação

\footnotetext{
1 A presente pesquisa adota o posicionamento de que "sexualidade e gênero são dimensões diferentes que integram a identidade pessoal de cada indivíduo. Ambos surgem, são afetados e se transformam conforme os valores sociais vigentes em uma dada época. São partes, assim, da cultura, construídas em determinado período histórico, ajudando a organizar a vida individual e coletiva das pessoas. Em síntese, é a cultura que constrói o gênero, simbolizando as atividades como masculinas e femininas" (BRASIL, 2009, p. 46). 4

2 Opta-se pela utilização da sigla LGBTI para definir o movimento de Lésbicas, Gays, Bissexuais, Transgêneros (travestis e transexuais) e Intersexos, por ser aquela utilizada pelas Nações Unidas no Brasil (ONU BRASIL, 2019). Todavia, reconhece-se a existência - e relevância - de pesquisas que ainda incluem junto à sigla a letra $\mathrm{Q}$, de queer, para contemplar pessoas não-binárias. Em que pese não utilizar a sigla LGBTQI+, ou outras variações, o trabalho objetiva o enfrentamento das questões de gênero e diversidade sexual que ameaçam ou violam direito a qualquer pessoa, independentemente da forma com que ela venha a se identificar, sejam elas: lésbicas, gays, bissexuais, transgêneros, travestis, transexuais, intersexos, assexuais, pansexuais, indivíduos não-binários ou quaisquer outros que sofrem discriminação em razão de sua orientação sexual ou da forma como manifestam/reconhecem o seu gênero.
} 
para reconhecimento das diferenças, promove a igualdade de gênero e auxilia na construção da cidadania para mulheres negras.

Dito isso, o presente artigo - que integra parte de pesquisa em desenvolvimento, com bolsa da Coordenação de Aperfeiçoamento de Pessoa de Nível Superior - Brasil (CAPES) - Código de Financiamento oo1, consiste em um trabalho de caráter descritivo, bibliográfico e documental, e se vale dos ideais de cidadania, enquanto “direito a ter direitos" (ARENDT, 2012, p. 403), e do respeito à igualdade pela diferença, tal como proposto por Santos (2003, p. 56).

Para tanto, será dividido em duas seções. A primeira se ocupará de demonstrar a importância da educação para a construção da cidadania e do espaço escolar para o reconhecimento das diferenças e promoção da não-discriminação. A segunda se ocupará de demonstrar de que forma a Educação em Gênero e Diversidade sexual pode promover a igualdade de gênero e quais os possíveis reflexos em contraste com a atual realidade da população feminina negra.

Como resultado da presente pesquisa, pretende-se elevar a visibilidade e reunir informações que possibilitem futuros estudos acerca do tema, bem como abordar a Educação em Gênero e Diversidade Sexual na promoção da igualdade de gênero, em especial da população negra do país.

\section{A educação para a conquista da cidadania}

A concepção de cidadania teve início na Antiguidade clássica, estando atrelada à participação política, porém de apenas uma parcela da população. Ao longo dos milênios subsequentes, a ideia do ser cidadão sofreu algumas alterações quanto à sua definição, indo além do viés político. Porém, ainda hoje, sua fruição continua limitada a um determinado grupo minoritário, seja em função da posição social, seja em razão nacionalidade, ou mesmo do gênero, dentre outros fatores (SMANIO, 2015, p. 1).

No Brasil, a noção de cidadania está prevista no artigo $1^{\circ}$, inciso II, da Constituição de República Federativa do Brasil de 1988 (BRASIL, 1988) como um fundamento constitucional, e que para ser efetivada necessita de um conjunto de prestações fáticas e jurídicas. Arendt (2012, p. 403), entende a cidadania como sendo o "direito a ter direitos", ou seja, para que exista a cidadania, portanto, é preciso que a atuação estatal esteja voltada à tutela total do indivíduo, reconhecendo-o como sujeito de direitos em diferentes dimensões: educacional, política, econômica, cultural, social, etc.

Segundo Barco,

Las acciones, normas o estrategias que utilicen los Estados deberán ser medidas por su impacto en protección y promoción de los derechos de los seres humanos y no bajo criterios de eficiencia de ejecución de actividades. Entonces, el Estado debe actuar garantizando los derechos humanos, incorporando la visión de que 
el eje central es el ser humano y que el objetivo de sus acciones es que hombres y mujeres [y grupo LGBTI] puedan ejercer de manera plena sus derechos (BARCO, 2014, p. 66)3.

Dentre as formas de se gozar os direitos de cidadania, está a educação, tida como um direito constitucional e vetor de máxima importância de inclusão na sociedade a ser "promovida e incentivada [...], visando ao pleno desenvolvimento da pessoa, seu preparo para o exercício da cidadania e sua qualificação para o trabalho" (BRASIL, 1988). A educação, dessa forma, emerge como meio de efetivação da cidadania em seu sentido lato sensu, isto é, de direitos civis, políticos (da liberdade), sociais, econômicos, culturais (da igualdade), dentre outros inerentes à dignidade humana.

Como se observa, a construção da cidadania está interligada à plena realização do indivíduo, perpassando liberdades e igualdades. Para tanto, é preciso que se dissociem os conceitos de diferença e desigualdade, o que nos remonta aos ensinamentos de Santos (2003, p. 51), pelo qual:

[...] temos o direito a ser iguais quando a nossa diferença nos inferioriza; e temos o direito a ser diferentes quando a nossa igualdade nos descaracteriza. Daí a necessidade de uma igualdade que reconheça as diferenças e de uma diferença que não produza, alimente ou reproduza as desigualdades.

Tanto é assim, que Davis (1983, p. 61) traz em sua obra Women, Race and class que: "The most outstanding examples of white women's sisterly solidarity with Black women are associated with Black people's historical struggle for education"4.

Nessa perspectiva, o espaço escolar torna-se lugar privilegiado para debate sobre as diferenças. Por isso,

A ampliação dos investimentos em educação, bem como a criação e reformulação de políticas educacionais se fazem necessárias para que os objetivos relacionados às melhorias sociais e econômicas sejam alcançados. Uma dessas melhorias diz respeito à diminuição da desigualdade de gênero no campo da educação, tanto com relação à inserção de mulheres e meninas na educação quanto à uma maior preocupação em se trazer a discussão sobre gênero para esse campo (CHRISPIANO; RIBEIRO, 2017, p. 22). (grifo nosso)

3 Tradução livre: "As ações, normas ou estratégias utilizadas pelos Estados devem ser medidas pelo seu impacto na proteção e promoção dos direitos humanos e não em critérios de eficiência na execução das atividades. Então, o Estado deve atuar garantindo os direitos humanos, incorporando a visão de que o eixo central é o ser humano e que o objetivo de suas ações é que homens e mulheres [e grupo LGBTI] possam exercer plenamente seus direitos".

4 Tradução livre: Os exemplos mais marcantes de sororidade que as mulheres brancas tinham em relação às mulheres negras estão associados à histórica luta do povo negro por educação. 
A Educação em Gênero e Diversidade Sexual, observada a atenção pedagógica que a abordagem dos assuntos demanda, estabelecendo critérios de qualidade informacional e de condições psicopedagógicas de acordo com as faixas etárias dessas crianças e adolescentes, à vista disso, reconhece que é no meio educacional onde se vivencia muitas vezes pela primeira vez a fruição de direitos, e é também nesse meio que se verificam práticas discriminatórias e segregadoras contra o "outro", o diferente. Moreira (2017, p. 208) afirma que

[...] a discussão sobre sexualidade também é uma discussão sobre a democracia, sobre a integração de grupos nas diferentes esferas da vida em comunidade. Esse debate também é relevante para a criação de uma educação para a democracia, algo decorrente da necessidade de criação de canais sociais de preparação para a realidade do pluralismo social.

De igual modo, segundo Louro (2000, p. 09), "[...] as sociedades realizam esses processos e, então, constroem os contornos demarcadores das fronteiras entre aqueles que representam a norma que estão em consonância com seus padrões culturais e aqueles que ficam de fora dela, às suas margens".

Além disso, é preciso compreender que as demarcações de normalidade/ anormalidade no que se refere à gênero e diversidade sexual estão presentes em diferentes espaços, dentre os quais a própria escola. Bento (2008, p. 129) pontua que

[...] a escola, que se apresenta como uma instituição incapaz de lidar com a diferença e pluralidade, funciona como uma das principais instituições guardiãs das normas de gênero e produtora da heterossexualidade. Para os casos em queas crianças são levadas a deixar a escola por não suportarem o ambiente hostil é limitador falarmos em "evasão". No entanto, não existem indicadores para medir a homofobia de uma sociedade e, quando se fala na escola, tudo aparece sob o manto invisibilizante da evasão. Na verdade há um desejo em eliminar e excluir aqueles que contaminam o espaço escolar. Há um processo de expulsão e não de evasão.

Assim, a Educação em Gênero e Diversidade Sexual, ao promover o reconhecimento/respeito às diferenças de gênero e diversidade sexual, aproximase do ideal de cidadania como "direito a ter direitos", atuando com duplo efeito: de um lado, permitindo ao aluno que sofre ameaças/lesões a Direitos Humanos se reconhecer como sujeito de direitos, e de outro, permitindo que o aluno que pratica discriminação/violência com base em gênero e diversidade sexual possa assimilar práticas inclusivas de respeito às diferenças, considerando as mais diversas possibilidades de construções identitárias. 
Além disso, a difusão de conteúdos que versam sobre gênero e diversidade sexual tem como efeitos, dentre outros, a promoção da igualdade de gênero para mulheres cis ou trans. Pedra (2018, p. 15) entende que

Sem a garantia da dignidade e igualdade (uma vez que para todos), um grupo social não pode se considerar (nem ser considerado) capaz de exercer sua cidadania. É preciso, para isso, verificar os pontos de exclusão dessas pessoas e as formas de corrigir essas barreiras. Para o planejamento de políticas públicas e medidas de intervenção na realidade que sejam capazes de aproximar esses grupos do exercício da cidadania, é preciso, então, que o Poder Público consiga entender, se situar e se lançar num contexto tão diferenciado e marcado pelas interseccionalidades que constituem o Movimento LGBT e sua luta por cidadania. As reivindicações e pautas desse movimento incluem, em todos os momentos, recortes de gênero, raça, idade, classe social, pertencimento religioso e uma série de diversidades. E, na especificidade das pessoas trans, ainda é preciso considerar o caráter multifacetado das exclusões vivenciadas.

Assim, verifica-se que "[...] da identidade, da diferença e do outro é um problema pedagógico e curricular, especialmente, se o outro é o outro gênero, é a cor diferente, é a outra sexualidade, é a outra etnia, é a outra nacionalidade, é o corpo diferente. Problema maior ainda quando o outro não é aceito pela própria escola" (FERREIRA; LUZ, 2009, p. 41), razão pela qual abordar a educação em gênero e diversidade sexual torna-se ímpar na conjuntura atual e para as próximas décadas, com currículos trabalhados nesse sentido.

Em que pesem as tentativas de se limitar/proibir a abordagem dos temas de gênero e diversidade sexual em sala de aula, especialmente considerando-se a tramitação do Projeto de Lei no 246/2019 (BRASIL, 2019), que objetiva a inclusão, dentre as diretrizes e bases da educação nacional, do programa "Escola Sem Partido" e veda a difusão de conteúdos que abordam questões de gênero e diversidade sexual nas salas de aula, acompanha-se o posicionamento de Louro (1997, p. 81), pela qual:

Essa presença da sexualidade independe da intenção manifesta ou dos discursos explícitos, da existência ou não de uma disciplina de "educação sexual", da inclusão ou não desses assuntos nos regimentos escolares. A sexualidade está na escola porque ela faz parte dos sujeitos, ela não é algo que possa ser desligado ou algo do qual alguém possa se "despir".

Temer (2018, p. 446) ainda afirma que: 
[...] tratar de questões referentes a gênero e orientação sexual envolve dignidade humana, igualdade, direitos fundamentais, não-discriminação, autodeterminação e liberdades individuais. Tais direitos e valores não só ultrapassam, e muito, o âmbito municipal, como superam inclusive as barreiras nacionais.

Para que homens e mulheres sejam materialmente "iguais em direitos e obrigações" (BRASIL, 1988),

\begin{abstract}
Espera-se, portanto, que uma prática educativa de enfrentamento das desigualdades e valorização da diversidade vá além, seja capaz de promover diálogos, a convivência e o engajamento na promoção da igualdade. Não se trata, simplesmente, de desenvolver metodologias para trabalhar a diversidade e tampouco com "os diversos". É, antes de tudo, rever as relações que se dão no ambiente escolar na perspectiva do respeito à diversidade e de construção da igualdade, contribuindo para a superação das assimetrias nas relações entre homens e mulheres, entre negros/as e brancos/as, entre brancos/as e indígenas entre homossexuais e heterossexuais e para a qualidade da educação para todos e todas. (BRASIL, 2009, p. 34)
\end{abstract}

Com a aplicação da Educação em Gênero e Diversidade Sexual para reconhecimento das diferenças e promoção da igualdade de gênero para a conquista da cidadania, o espaço escolar emerge como ferramenta inclusiva e democrática. Resta compreender de que forma esse tipo de educação pode ser utilizado no enfrentamento às problemáticas de gênero para mulheres negras, tema que é explorado no próximo item.

\title{
Educação em Gênero e Diversidade Sexual e igualdade de gênero para mulheres negras
}

Conforme demonstrado no item anterior, a educação voltada às questões de gênero e diversidade sexual tem por objetivo promover a cidadania enquanto "direito a ter direitos" (ARENDT, 2012, p. 403), bem como propalar uma lógica de reconhecimento/respeito às diferenças (SANTOS, 2003, p. 51) apta a transformar as relações de gênero e diversidade sexual em diferentes espaços, dentre os quais destaca-se o próprio ambiente escolar.

De acordo com Buttler (2003, p. 25) o tema gênero não está ligado somente ao entendimento dual masculino e feminino, pois "[...] o gênero não está para a cultura como o sexo para a natureza”. Desse modo, o tema envolve tanto a heterossexualidade, quanto a homossexualidade; bem como a cisgeneridade e a transgeneridade. 
O fato é que numa cultura patriarcal e androcentrista, apregoada no ordenamento jurídico de países tanto do oriente quanto do ocidente, tanto os grupos que compõem o grupo LGBTI, isto é, lésbicas, gays, bissexuais, travestis, transexuais e intersexuais, quanto as mulheres, são colocados numa condição de vulnerabilidade. Nesse sentido, Pisciteli (2012, p. 443) dispõe que

Considerar construções culturais as noções de masculinidade e feminilidade é relevante para todas as áreas do direito, da formulação de leis às diversas instâncias em que a Justiça se distribui. Deve-se, portanto, compreender como nessas dimensões se pode reforçar ou, em vez disso, deslocar noções que interferem na criação e na manutenção de hierarquias e desigualdades relacionadas às mulheres e às demais categorias de pessoas situadas em situações de inferioridade em decorrência de construções de gênero.

Castañeda (2006, p. 28), por sua vez, defende que:

[...] explicações do machismo, derivadas de estudos de gênero, da antropologia e da etnografia, da sociologia e da história, baseiamse em fatores sociais, econômicos e culturais para afirmar que o machismo não é inato da biologia: é aprendido. Existem diversas maneiras de ser homem e cada sociedade tem seu próprio ideal masculino - que não é necessariamente machista, ou não da mesma maneira - conforme suas condições econômicas e sociais.

De forma similar, Bertolin e Baruki (2010, p. 305) ainda ressaltam que "a sociedade patriarcal [...] encarrega-se de incutir na mulher um sentimento de inferioridade que sustentará o mecanismo de culpabilização, necessário à perpetuação da submissão, do servilismo e da sujeição", além de discriminar o outro: o diferente do ideário social, no qual se inserem o grupo LGBTI e, para fins desse artigo, mulheres trans e travestis.

O gênero feminino, portanto, torna-se um agravante para a fruição de direitos inerentes à pessoa humana, além de alvo de recorrentes violências e mitigação de direitos, tais como violência doméstica, assédio sexual, menores salários. Em sentido similar, se percebe que mulheres trans (e especialmente travestis) também vivenciam situações de discriminação e violências em razão da forma como se reconhecem e expressam o seu gênero, muitas vezes em circunstâncias piores se comparadas às das mulheres cis.

Roughgarden (2016, p. 73) ressalta que gênero é uma construção cultural na qual um dos elementos constitutivos seria o sexo (mas não necessariamente a sexualidade), e destaca que: 
O gênero, ao contrário do sexo, é normalmente considerado pertencente unicamente aos seres humanos, algo que é construído pela cultura e uma expressão altamente divergente em diferentes culturas. O que poderia significar gênero enquanto aplicados aos animais? Para os animais, considero gênero a aparência, o comportamento e a história de vida de um corpo sexuado, que é um corpo classificado de acordo com o tamanho dos gametas produzidos. Assim, o gênero é a aparência mais a ação - como um organismo usa sua morfologia (cor e forma) e comportamento para desempenhar um papel reprodutivo. (tradução nossa)

Na percepção de Mackinnon (1989), ser homem ou mulher nas sociedades é algo inerente à identidade da pessoa humana, porém a sexualidade é uma forma de poder e a heterossexualidade (masculina) instrumentaliza a submissão. A partir disso,

Os corpos ganham sentido socialmente. A inscrição dos gêneros - feminino ou masculino - nos corpos é feita, sempre, no contexto de uma determinada cultura e, portanto, com as marcas dessa cultura. As possibilidades da sexualidade - das formas de expressar os desejos e prazeres - também são sempre socialmente estabelecidas e codificadas. As identidades de gênero e sexuais são, portanto, compostas e definidas por relações sociais, elas são moldadas pelas redes de poder de uma sociedade (LOURO, 2000, p. 09).

Quando se relaciona a questão do gênero em uma perspectiva étnico-racial, por sua vez, percebe-se que a violação aos direitos das mulheres negras, sejam elas cis ou trans, é ainda mais agravada, tendo em vista o próprio histórico do negro no Brasil.

Nesse sentido, podemos destacar a obra de Freyre (1992, p. 22) "Casa Grande e Senzala”, que traz um resumo do cenário da sociedade brasileira, em especial da mulher preta e parda, no período colonial e escravocrata, afirmando que

[...] a mulher morena tem sido a preferida dos portugueses para o amor, pelo menos para o amor físico. A moda de mulher loura, limitada, aliás, às classes altas, terá sido antes a repercussão de influências exteriores do que a expressão de genuíno gosto nacional. Com relação ao Brasil, que o diga o ditado: "Branca para casar, mulata para f... negra para trabalhar", ditado em que se sente, ao lado do convencialismo social da superioridade da mulher branca e da inferioridade da preta, a preferência sexual da mulata. 
Desde então, verifica-se uma grande distinção entre as mulheres brancas, pretas e pardas, tanto no que tange ao trato, como no acesso a direitos e excesso de encargos como trabalhadoras, apesar dos avanços diante dos movimentos de feminização negra desde a década de 1970 e do aumento visibilidade aos olhos da sociedade civil como sujeitos políticos, ainda se percebe um pouca atuação do Poder Público nessa seara, tendo em vista que "[...] a interpretação do sexismo como fenômeno histórico [tem] sua intrínseca articulação em outro fenômeno também de profundidade histórica e de caráter estruturante nas sociedades, o racismo" (BONFIM, 2009, p. 223), tema ainda tabu dentro do estado brasileiro. Com isso,

As mulheres negras têm sido, ao longo de sua história, as maiores vítimas da desigualdade de gênero somada à racial, pois, os estudos realizados revelam um quadro dramático que não está apenas nas precárias condições socioeconômicas em que vivem, mas sobretudo, na negação cotidiana de ser mulher negra, através do racismo e do sexismo que permeiam todas as esferas de sua vida (BANDEIRA; BITTENCOURT, 2005, p. 179).

Historicamente, com o advento do século XX, tendo por influência os movimentos negros dos Estados Unidos da América na segunda metade do Século XX, mediante convenções locais e nacionais (DAVIS, 1983, p. 41), tais movimentos também começaram a despontar no Brasil, e houve o crescimento da representatividade das mulheres negras, via grupos feministas, bem como de gays e lésbicas mediante seus coletivos.

A temática do feminismo negro emerge como necessária para a promoção da igualdade entre os gêneros, especialmente aquele que visa corrigir problemas como preconceitos raciais e econômicos. Sobre o feminismo negro:

Existe uma teoria que divide o movimento feminista em três momentos, denominados Ondas Feministas. A Primeira Onda Feminista seria aquela ocorrida nos meados de 1848, que reivindicou igualdade contratual, iguais oportunidades de adquirir bens, direito ao voto e também o fim dos casamentos arranjados que desrespeitavam o direito de escolha da mulher. A Segunda Onda Feminista, na década de 6o, seria a continuação da primeira, porém com o movimento mais encorpado, com mais adeptas e lutando pela igualdade em todos os âmbitos sociais. A terceira fase, que começou por volta dos anos 9o, preocupou-se em corrigir as falhas de suas antecessoras, principalmente dando maior visibilidade as minorias dentro do próprio movimento, como as mulheres de baixa renda, as negras e as lésbicas (DIAS, 2016, p. 473). (grifo nosso) 
De acordo com os dados apresentados pelo IPEA por meio do relatório "Retrato das Desigualdades de Gênero e Raça: 20 anos", produzido com base em séries históricas de 1995 a 2015 da Pesquisa Nacional por Amostra de Domicílios (Pnad), do IBGE, no que se refere à situação educacional da população negra tem-se que:

[...] entre 1995 e 2015, a população adulta negra com 12 anos ou mais de estudo passou de 3,3\% para $12 \%$. Entretanto, o patamar alcançado em 2015 pelos negros era o mesmo que os brancos tinham já em 1995. Já a população branca, quando considerado o mesmo tempo de estudo, praticamente dobrou nesses 20 anos, variando de $12,5 \%$ para $25,9 \%$ (IPEA, 2017b).

No que se refere especificamente à educação da mulher negra, o relatório ainda ressalta que, em 2015, estas apresentavam baixa média de anos de estudos (IPEA, 2017a, p. 10), conforme se observa:
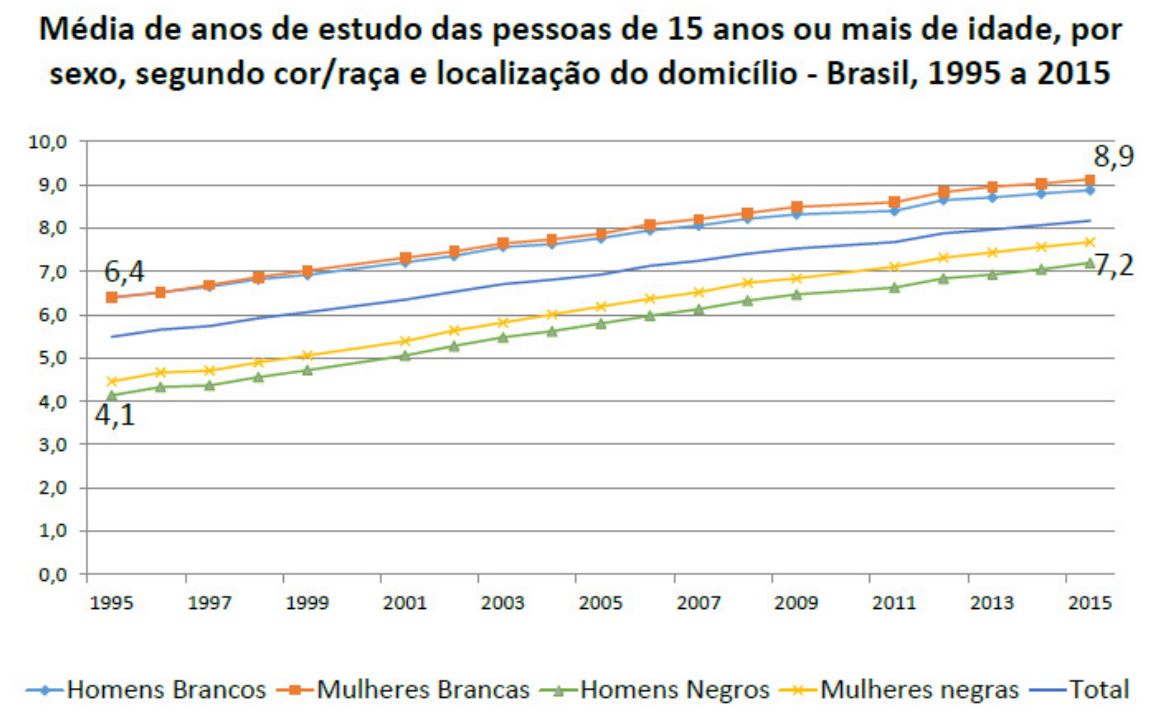

"Idoso: 60 anos ou mais
Fonte: Pnad/ IBGE Elaboração: IPEA/DISOC/NINSOC

Além disso, com relação aos critérios de rendimento e taxa de ocupação:

Apesar de, proporcionalmente, o rendimento das mulheres negras ter sido o que mais se valorizou entre 1995 e 2015 (80\%), e o dos homens brancos ter sido o que menos cresceu (11\%), a escala de remuneração manteve-se inalterada em toda a série histórica: homens brancos têm os melhores rendimentos, seguidos de mulheres brancas, homens negros e mulheres negras. A diferença da taxa de desocupação entre sexos também merece registro: em 2015, a feminina era de 11,6\%, enquanto a dos homens atingiu $7,8 \%$. No caso das mulheres negras, ela chegou a $13,3 \%$ (e 8,5\% para homens negros) (IPEA, 2017b). (grifos nossos) 
Ao se tratar da violência com base em elementos de gênero e raça, tem-se que:

[...] dentro de uma realidade de violência, o quadro mais alarmante diz respeito às mulheres negras, pois a década de 2003 a 2013 evidencia um aumento de $54,2 \%$ no total de assassinatos desse grupo étnico, saltando de 1.864, em 2003, para 2.875, em 2013. Aproximadamente mil mortes a mais em 10 anos. Esses dados são do Mapa da Violência de 2015: Homicídios de Mulheres no Brasil, [...] o estudo denuncia que, em 2013, morreram assassinadas, proporcionalmente ao tamanho das respectivas populações, $66,7 \%$ mais meninas e mulheres negras do que brancas, segundo o Portal Brasil. São dados que lamentavelmente colocam as mulheres negras em um medonho e sinistro ranking: as maiores vítimas de homicídio no país. Nascer mulher já é um grande risco em praticamente todas as culturas. Nascer mulher e negra se torna um perigo ainda maior. $E$ as condições de periculosidade aumentam, dependendo da condição social, do local e da cultura. No Brasil, se for lésbica, transmulher, por exemplo, as condições para a violência são maiores (SAMPAIO; CANDIOTTO; PILLA, 2016, p. 225). (grifo nosso)

De igual forma, o relatório Visível e invisível, produzido pelo Instituto Datafolha, apresenta os dados mais relevantes no que se refere à vitimização de mulheres no país, como se vê:

Vale destacar que em uma década (a pesquisa abarcou o período de 2003 a 2013) os feminicídios contra negras aumentaram $54 \%$, ao passo que o índice de mortes violentas de mulheres brancas diminuiu 9,8\%. Em uma década, o índice de vitimização das negras - cálculo que resulta da relação entre as taxas de mortalidade de ambas as raças - cresceu 190,9\% em todo o País, número que ultrapassa os 300\% em alguns Estados, como Amapá, Pará e Pernambuco (2017, p. 38).

No que se refere às mulheres trans negras, o Mapa dos assassinatos de Travestis e Transexuais no Brasil produzido pela Associação Nacional de Travestis e Transexuais (ANTRA), demonstra que, em 2017, ocorreram "179 Assassinatos de pessoas Trans, sendo 169 Travestis e Mulheres Transexuais e 10 Homens Trans" (ANTRA, 2018, p. 14), bem como que "a cada 48h uma pessoa Trans é assassinada no Brasil e que a idade média das vítimas dos assassinatos é de 27,7 anos" (ANTRA, 2018, p. 16). Ou seja, em 2017, "94\% dos assassinatos foram contra pessoas do gênero feminino" (ANTRA, 2018, p. 19) e, em relação à raça das vítimas, "80\% dos casos foram identificadas como pessoas negras e pardas” (ANTRA, 2018, p. 18).

Pelos dados acima colacionados, infere-se que, de forma geral, "[...] todas as mulheres padecem à discriminação de gênero e outras formas de violência dela 
decorrentes. Entre a população brasileira, as mulheres pobres, negras e transgêneros são aquelas mais vitimizadas" (SAMPAIO; CANDIOTTO; PILLA, 2016, p. 216).

Constatada a necessidade de se promover uma verdadeira transformação social no que toca às questões de gênero e diversidade sexual, a Educação em Gênero e Diversidade Sexual poderia ser utilizada para contornar a realidade de mulheres negras ao difundir noções de respeito às diferenças e não-discriminação?

O Plano Nacional de Educação em Direitos Humanos (2007, p. 51) traz como uma de suas ações programáticas:

[...] 10. fomentar ações educativas que estimulem e incentivem o envolvimento de profissionais dos sistemas com questões de diversidade e exclusão social, tais como: luta antimanicomial, combate ao trabalho escravo e ao trabalho infantil, defesa de direitos de grupos sociais discriminados, como mulheres, povos indígenas, gays, lésbicas, transgêneros, transexuais e bissexuais (GLTTB), negros(as), pessoas com deficiência, idosos(as), adolescentes em conflito com a lei, ciganos, refugiados, asilados, entre outros.

Assim, a Educação em Gênero e Diversidade Sexual, como espécie do gênero Educação em direitos Humanos, emerge como uma ferramenta para a

[...] transformação social necessária para findar as desigualdades de gênero que ainda persistem em nosso país. Isso pode ser atribuído, em grande parte, à nossa persistente cultura machista, que não reconhece a igualdade entre homens e mulheres como um valor democrático e de justiça social, e que, portanto, não referenda iniciativas que tenham por objetivo a promoção dessa igualdade. Assim, qualquer aparato institucional destinado à implementação de políticas para as mulheres enfrenta não somente a resistência simbólica, como também dificuldades de atuação, sobretudo porque deve atuar primordialmente na articulação com as demais instâncias de governo (IPEA, 2018, p. o9).

Ao difundir preceitos de Direitos Humanos e promover a igualdade entre os gêneros no ambiente escolar, a partir de práticas escolares inclusivas, com enfrentamento de discriminações e superação de misoginia, machismo, sexismo, transfobia, racismo, dentre outros, expandir-se-á, também, a cidadania para mulheres negras, uma vez que

[...] a baixa participação das mulheres na política institucional, as diferenças salariais entre homens e mulheres, a ocupação maciça por mulheres de postos de trabalho que reproduzem estereótipos 
de gênero, questões relacionadas à forma como a saúde da mulher é tratada pelo Estado, entre outros tantos aspectos, precisam ser enfrentados por meio de políticas públicas específicas (IPEA, 2018, p. 21).

Dessa forma, a Educação em Gênero e Diversidade Sexual, enquanto educação para reconhecimento das diferenças, fundamenta-se como política pública voltada à igualdade de gênero e auxilia na construção da cidadania para mulheres negras, sejam elas cis ou trans.

\section{Considerações finais}

A Educação em Gênero e Diversidade Sexual, ao promover o reconhecimento/ respeito às diferenças de gênero e diversidade sexual, aproxima-se do ideal de cidadania como "direito a ter direitos". Sua aplicação junto às crianças e adolescentes, no que se refere à temática de gênero, é política pública de enfrentamento a diferentes discriminações e, mais que isso, permite que tanto o aluno que pratica, quanto aquele que sofre ameaças/lesões a Direitos Humanos com base em gênero reconheçam a si e ao próximo como sujeito de direitos.

Por outro lado, a partir dos índices apresentados, verifica-se uma realidade aterradora para as mulheres, especialmente mulheres negras. Mesmo com debates sobre a temática, produção de leis e jurisprudências e a atuação de movimentos de feminismo negro ainda não fora possível dissociar-se das origens coloniais que ora objetificam, ora vulnerabilizam mulheres negras na sociedade: privando-lhes de direitos e do acesso a diferentes espaços/oportunidades. Em se tratando de mulheres trans negras - incluindo-se aqui, também, as travestis -, por sua vez, os reflexos da discriminação são ainda piores: resultam em violência ou total marginalização.

A educação, dessa forma, emerge como meio de efetivação da cidadania em seu sentido lato sensu, isto é, de direitos civis, políticos (da liberdade), sociais, econômicos, culturais (da igualdade), dentre outros inerentes à dignidade humana. A Educação em Gênero e Diversidade sexual, enquanto modalidade de Educação em Direitos Humanos, vai além: permite ainda que o estudante assimile práticas inclusivas de respeito às diferenças, descontrua estereótipos de gênero e conviva harmoniosamente com as mais diversas possibilidades de construções identitárias. 


\section{Referências bibliográficas}

ANTRA - Associação Nacional de Travestise Transexuais. (2018). Mapa dos Assassinatos de Travestis e Transexuais no Brasil em 2017. Disponível em: <https://antrabrasil.files. wordpress.com/2018/02/relatc3b3rio-mapa-dos-assassinatos-2017-antra.pdf $>$. Acesso em: 10 dez. 2018.

ARENDT, Hannah. As Origens do Totalitarismo. Tradução de Roberto Raposo. São Paulo: Companhia de Bolso, 2012.

BANDEIRA, Lourdes; BITTENCOURT, Fernanda. (2005). "Desafiosdatransversalidade de gênero nas políticas públicas brasileiras”. In: SWAIN, T. N.; MUNIZ, D. do C. G. Mulheres em ação, práticas discursivas, práticas políticas. Florianópolis: Ed. Mulheres; Belo Horizonte: PUC Minas. p. 169-193.

BARCO. Carlos Alza (2014). “El Enfoque basado en Derechos ¿Qué es yo Cómo se aplica a las Políticas Públicas?” In: BURGOIGUE-LARSEN, Laurence. MAUÉS, Antonio. MOJICA, Beatriz Eugenia Sánchez. (Coord.) DHES. Derechos Humanos y Educación Superior: Manual de Derechos Humanos y Políticas Públicas. Barcelona: Universitat Pompeu Fabra. p. 51-78.

BRASIL. Senado Federal (1988). Constituição Federal de 1988. Texto Promulgado em 05/10/1988. Disponível em: <https://www.senado.gov.br/atividade/const/con1988/ CON1988_05.10.1988/art_205.asp>. Acesso em: 10 dez. 2018.

BRASIL. (2007). Plano Nacional de Educação em Direitos Humanos. Comitê Nacional de Educação em Direitos Humanos. - Brasília: Secretaria Especial dos Direitos Humanos, Ministério da Educação, Ministério da Justiça, UNESCO.

BRASIL. (2009). Gênero e Diversidade na Escola - Formação de Professoras/es em Gênero, Sexualidade, Orientação Sexual e Relações Étnico-Raciais. Rio de Janeiro: CEPESC; Brasília: SPM, 20o9. Disponível em: <http://estatico.cnpq.br/portal/ premios/2014/ig/pdf/genero_diversidade_escola_2009.pdf>. Acesso em: o1 dez. 2018.

BRASIL. (2012). Encontro debate políticas públicas para negros, negras e LGBT. Disponível em:<http://www.brasil.gov.br/cidadania-e-justica/2012/11/encontrodebate-politicas-publicas-para-negros-negras-e-lgbt>. Acesso em: 14 de dez 2018.

BRASIL. (2015). Projeto de Lei no 867, de 2015. Inclui, entre as diretrizes e bases da educação nacional, o "Programa Escola sem Partido". Câmara dos Deputados. Brasília, 2015. Disponível em: <http://www.camara.gov.br/sileg/integras/1317168.pdf>. Acesso em: 10 dez. 2018. 
BRASIL. (2017a). IPEA. Retrato das desigualdades de gênero e raça: 20 anos. Instituto de Pesquisa Econômica Aplicada - Ipea. Disponível em: <http://www.ipea.gov.br/portal/ images/stories/PDFs/170306_apresentacao_retrato.pdf>. Acesso em 10 dez. 2018.

BRASIL. (2017b). IPEA. Estudo mostra desigualdades de gênero e raça em 20 anos. Instituto de Pesquisa Econômica Aplicada. Disponível em: <http://www.ipea.gov.br/portal/index. php?option=com_content\&view=article\&id=29526>. Acesso em: 10 dez. 2018.

BRASIL. (2018). IPEA. Políticas Sociais: acompanhamento e análise. Igualdade de gênero. Disponível em: <http://www.ipea.gov.br/portal/images/stories/PDFs/ politicas_sociais/171215_bps_25_igualdade_de_genero.pdf >. Acesso em: 10 dez. 2018.

BRASIL. (2019). Projeto de Lei no. 246/2019. Institui o "Programa Escola sem Partido". Câmara dos Deputados. Brasília. Disponível em: <https://www.camara.leg.br/ proposicoesWeb/prop_mostrarintegra? codteor=1707037\&filename=PL+246/2019>. Acesso em: 10 jan. 2019.

BONFIM, Vânia Maria da Silva. (2009). "A identidade contraditória da mulher negra brasileira: bases históricas”. In: NASCIMENTO, Elisa Larkin (Org.). Afrocentricidade: uma abordagem epistemológica inovadora. São Paulo: Selo Negro. p. 219-249.

BUTLER, Judith. (2003). Problemas de Gênero: feminismo e subversão da identidade. Rio de Janeiro: Civilização Brasileira.

BARUKI, Luciana Veloso; BERTOLIN, Patrícia T. Martins. (2010). "Violência contra a mulher: a face mais perversa do patriarcado. Quem tem medo do lobo mau?" In: ANDREUCCI, Ana Cláudia P. Torezan; BERTOLIN, Patrícia T. Martins. (Orgs.) Mulher, Sociedade e Direitos Humanos. São Paulo: Rideel. p. 304-319.

BENTO, Berenice. A. (2008). O que é transexualidade. São Paulo: Brasiliense.

CASTAÑEDA, Marina (2006). O Machismo Invisível. São Paulo: A Girafa.

CATRACA LIVRE. (2017). Como é ser um LGBT negro em uma sociedade racista. Disponível em:<https://catracalivre.com.br/cidadania/como-e-ser-um-lgbt-negroem-uma-sociedade-racista/>. Acesso em: 13 de dez 2018.

CHRISPIANO, Giovanna Fidelis; RIBEIRO, Mariana Cardoso dos Santos. (2017). "Inserção feminina na educação: a diplomacia brasileira frente à desigualdade de gênero". In: RAMOS; Marcelo Maciel; CASTRO; Felipe Araújo; MORAES, Bernardo Supranzetti de (Orgs.). Diversidade, educação, cultura e arte: gênero e sexualidade em perspectivas. Belo Horizonte: Initia Via. p. 21-35. 
DATAFOLHA. Visível e invisível: a vitimização de mulheres no Brasil. 2017. Fórum Brasileiro de Segurança Pública. Disponível em: <http://www.forumseguranca.org. br/wpcontent/uploads/2017/o3/relatoriopesquisavs4.pdf>. Acesso em: 10 dez. 2018.

DAVIS, Angela Y. (1983). Women, Race and Class. Nova Iorque: Vintage.

DIAS, Ana Luiza Soares (2016). "Performance e feminismo: a relação entre corpo, arte e empoderamento feminino na América Latina”. In: VITAL, Ana Flávia; BARROS, Mateus Oliveira; ALMEIDA, Victor Afonso de (Orgs.) II Congresso de Diversidade Sexual e de Gênero: Caderno de resumos. Belo Horizonte: Initia Via. p. 472-475.

FERREIRA, Beatriz. LUZ, Nancy. S. da (2009). "Sexualidade e gênero na escola". In: LUZ, Nancy S. da; CARVALHO, Marília G. de; CASAGRANDE, Lindamir Salete. Construindo a igualdade na diversidade: gênero e sexualidade na escola. Curitiba: Ed. UTFPR. p. 33-46.

FREYRE, Gilberto (1992). Casa grande e senzala: formação da família brasileira sob o regime da economia patriarcal. Rio de Janeiro: Record.

LOURO, Guacira Lopes. (200o). O corpo educado. Guacira Lopes Louro (Org.). Tradução de Tomaz Tadeu da Silva. 2플 Ed. Belo Horizonte: Autêntica Editora.

LOURO, Guacira Lopes. (1997). Gênero, sexualidade e educação: uma perspectiva pósestruturalista. Petrópolis, RJ: Vozes.

MOREIRA, Adilson José (2017). Cidadania Sexual: estratégia para ações inclusivas. Belo Horizonte: Arraes Editores.

NAÇÕES UNIDAS DO BRASIL. LGBTI. Disponível em: https://nacoesunidas.org/ tema/lgbti/. Acesso em: 10 jan. 2019.

PEDRA, Caio Benevides. (2018). Acesso à cidadania por travestis e transexuais no Brasil: um panorama da atuação do Estado no enfrentamento das exclusões. Dissertação (Mestrado em Administração Pública). Fundação João Pinheiro, Escola de Governo Professor Paulo Neves de Carvalho.

PISCITELI, Adriana. (2012). "Sexo e Gênero". In: Antropologia e direito: temas antropológicos para estudos jurídicos. LIMA; Antônio Carlos de Souza (Org.). Brasília/ Rio de Janeiro/Blumenau: Associação Brasileira de Antropologia / laced / Nova Letra. p. 439-447. 
SAMPAIO, Darli de Fátima; CANDIOTTO, Jaci de Fátima Souza; PILLA, Maria Cecilia Barreto Amorim. (2016). "Gênero, violência e Direitos Humanos”. In: Teorias dos direitos humanos em perspectiva interdisciplinar. BUENO; GUEBERT (Orgs.). Curitiba: PUCPRess. p. 215-250.

SANTOS, Boaventura de Sousa. (2003). Reconhecer para libertar: os caminhos do cosmopolitanismo multicultural. Rio de Janeiro: Civilização Brasileira.

SMANIO, Gianpaolo Poggio (2015). "Cidadania e Políticas Públicas”. In: SMANIO, Gianpaolo Poggio. BERTOLIN, Patrícia Tuma M. BRASIL, Patrícia Cristina (Orgs). O Direito na Fronteira das Políticas Públicas. São Paulo: Mackenzie. p. 1-5.

TEMER, Thaís. (2018) “As leis e projetos de lei sobre 'ideologia de gênero' nas escolas: uma análise sob a perspectiva das competências legislativas em matéria educacional". In: RANIERI, Nina Beatriz Stocco; ALVES, Angela Limongi Alvarenga (Orgs.). Direito à educação e direitos na educação em perspectiva interdisciplinar. São Paulo: Cátedra UNESCO de Direto à Educação/Universidade de São Paulo (USP). p. 431-452. 